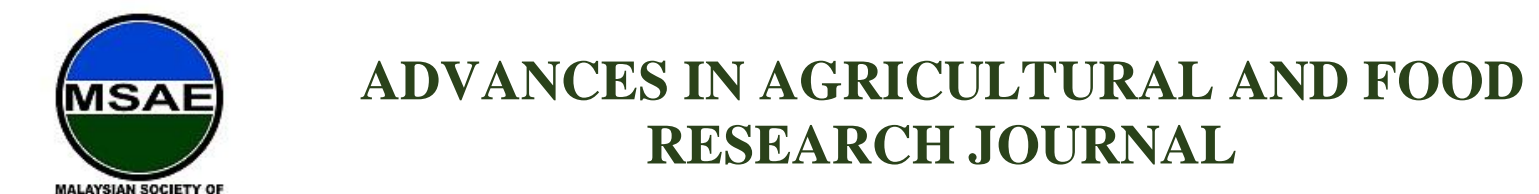

HH PUBLISHER

Original Research Article

\title{
Effect of Light Emitting Diode (LED) Spectra on Plant Growth
}

\begin{abstract}
Nur Syahirah Talib ${ }^{1}$, Diyana Jamaludin ${ }^{1 *}$, Nur Sakinah Abdul Malek ${ }^{1}$
${ }^{1}$ Department of Biological and Agricultural Engineering, Faculty of Engineering, Universiti Putra Malaysia, 43400 Serdang, Selangor, Malaysia

*Corresponding author: Diyana Jamaludin, Department of Biological and Agricultural Engineering, Faculty of Engineering, Universiti Putra Malaysia, 43400 Serdang, Selangor, Malaysia; diyana_upm@upm.edu.my.
\end{abstract}

Abstract: The effect of lights generated by red, blue and white light emitting diodes (LED) on growth and development of lettuce were investigated and compared with lettuce without supplemental lighting. A vertical multi-tier hydroponic system was used to grow lettuce. Each tier consisted of 60 heads of lettuce with different LED colour and one tier without LED was used as control. The following measurements on plant physiology were taken: number, length and chlorophyll content of leaves, height and weight of plants. Based on number of leaves, red LED shows the highest number of leaves compared to lettuce under blue, white and control treatment. The similar trend also can be found in the lengths of leaves which shows the highest length produce under red LED. Red LED also produce highest weight of lettuce by $28 \%$ as compared to white LED. White LED improved lettuce growth development in the height by $13 \%$ and amount of chlorophyll content. Lettuce grown under blue LED shows lowest growth and development compared to lettuce grown under red and white LEDs based on parameters above, and lettuce without LED were died within 2 weeks. This result indicated that the red LED was the most effective spectra in growth response of lettuce plants. This study also demonstrates the effectiveness of LED in improving lettuce growth on vertical multi-tier hydroponic system.

Keywords: light emitting diodes; growth; vertical; chlorophyll content; lettuce

Received: $6^{\text {th }}$ October 2020

Accepted: $7^{\text {th }}$ November 2020

Available Online: $24^{\text {th }}$ November 2020

Citation: Talib NS, Jamaludin D \& Abdul Malek, NS. Effect of light emitting diode (LED) spectra on plant growth. Adv Agri Food Res J 2020; 1(2): a0000135. https://doi.org/10.36877/aafrj.a0000135

\section{Introduction}

It is estimated that $53 \%$ of the world's population live in the urban area (MorenoMonroy et al., 2020) and the numbers keep increasing in which will lead to continuous demand of food source in urban area. In order to support higher demand of fresh food in urban area, some growers initiate to use limited area and space in the urban for agriculture activities. Urban agriculture is defined by the FAO as the growing of plants and the raising of animals within and around cities. Due to limited area and space available in urban, most 
of the structure design of crop production use the vertical, multi-tier with hydroponic system. However, one of the issues faced by the vertical farming system is the limited light exposure due to shading effect from the vertical tier itself. Light is known as the primary environmental factor for plant growth and development. Therefore, supplemental lighting was introduced to support crop growth and production in closed and shaded environment. Light Emitting Diode (LED) represent a promising technology as a grow lamps compared to conventional lighting using high pressure sodium (HPS) and fluorescent lamps. Some of the advantages of LEDs are the possibility to optimize lighting spectra to specific wavelength need by crop (Olle \& Virsile, 2013), energy saving in converting electrical energy to photon energy (Mitchell, 2012), minimal heat emission and longer lifetime (Bourget, 2008).

Table 1 shows the general wavelength effect to plant physiology. The photosynthetic active radiation (PAR) wavelength is the light use by plant for photosynthesis between 400 $760 \mathrm{~nm}$ encompass the blue $(425-490 \mathrm{~nm})$, red $(625-700 \mathrm{~nm})$ and far red $(700-740 \mathrm{~nm})$ light. Red light is usually the basal component which sufficient for plant growth and photosynthesis (Olle \& Virsile, 2013). It was also found that increasing the red LED intensity from 660 to $690 \mathrm{~nm}$ helps increase lettuce biomass (Goins et al., 1997). Blue LED is responsible for vegetative growth, and was reported to enhanced $\beta$ carotene in Kale plants (Lefsrund et al., 2008) and increased anthocyanin concentration in lettuce (Stutte et al., 2009). White LED was found to be more conductive to human eyes (Han et al., 2017) and designed to mimic natural light by providing plants a balanced spectrum of red, blue and green. In this study, effect of different light treatment on the lettuce growth; number, length and height of leaves, chlorophyll content, and weight of plants were measured.

Table 1. Wavelength effect on plant physiology.

\begin{tabular}{|c|c|c|}
\hline \multicolumn{2}{|c|}{ Wavelength (nm) } & Effect on Plant Growth \\
\hline UV (Ultraviolet) & 280 & Significantly reduce quantum yield and rate of photosynthesis \\
\hline & $315-400$ & $\begin{array}{l}\text { Promotes pigmentation, thickens plants leaves and may be used to } \\
\text { prevent harmful insects. }\end{array}$ \\
\hline \multirow[t]{5}{*}{ Visible Spectrum } & $440-470$ & $\begin{array}{l}\text { Chlorophyll absorption peaks at } 439 \mathrm{~nm} \text { and } 469 \mathrm{~nm} \text {. The blue } \\
\text { spectrum is the most efficiently absorbed spectrum, promoting } \\
\text { mainly vegetative growth. }\end{array}$ \\
\hline & 510 & $\begin{array}{l}\text { Quantum absorption in the green spectrum. Little absorption is the } \\
\text { yellow spectrum }\end{array}$ \\
\hline & 610 & $\begin{array}{l}\text { No chlorophyll benefit. Efficiently absorbed by algae phycoerythrin } \\
\text { and phycocyanin receptprs. }\end{array}$ \\
\hline & $640-660$ & $\begin{array}{l}\text { Chlorophyll absorption peaks at } 642 \mathrm{~nm} \text { and } 667 \mathrm{~nm} .660 \mathrm{~nm} \text { is the } \\
\text { most vital wavelength for flowering. Speeds up seed germination } \\
\text { and flower/ bed onset. }\end{array}$ \\
\hline & 740 & Increase the rate of photosynthesis \\
\hline Infrared & $1000-1400$ & No plant activity detected at this wavelength. Heat generated. \\
\hline
\end{tabular}

(Source: www.urbanvine.com) 


\section{Materials and Methods}

\subsection{System Design}

The multi-tier hydroponic structure has 5 tiers with $162 \mathrm{~cm}$ height and $120 \mathrm{~cm}$ width. Each tier had 2 units of rectangular tray which were connected with a small PVC pipe. Each rectangular tray consisted of 30 holes for plants which made up to 60 plants were grown on each treatment or tier (Figure 1). A fertigation tank with size of $59 \mathrm{~cm} \times 43 \mathrm{~cm} \times 37 \mathrm{~cm}$ was used as fertigation reservoir that pump in water with fertilizer into the hydroponic unit. Lettuce (Lactuca Sativa) seeds were sown inside a germination tray, watered and covered until seeds were germinated within 8-12 days. These seedlings were then transplanted to the peat disc (PD $24 \mathrm{~mm}$ ) as growing medium which made from coconut fibre that has faster water absorption and retention. Lettuce were then harvest after 30 days after transplant.

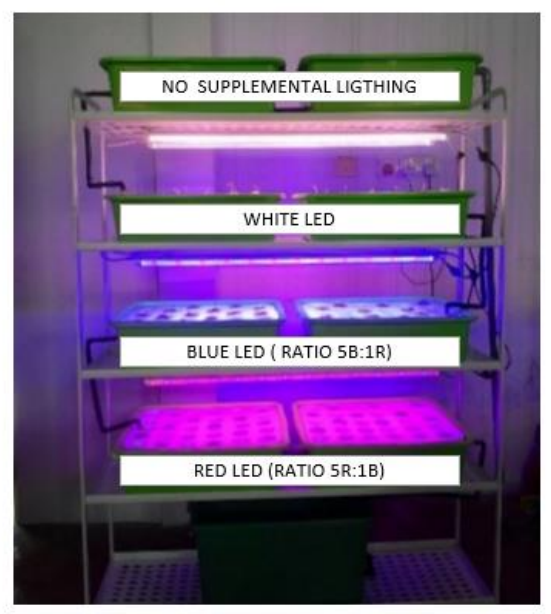

(a)

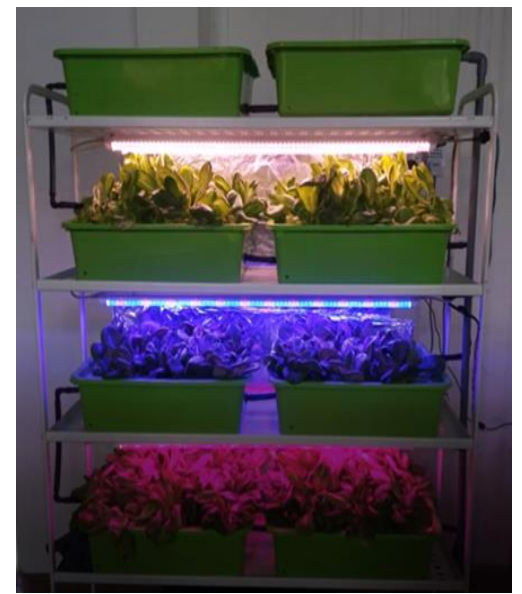

(b)

Figure 1. The vertical multi-tier hydroponic system; (a) initial project setup, (b) lettuce growth in the end of project.

\subsection{Light Treatment}

Four lighting LED treatments were compared; control unit with no supplemental lighting (on the top tier), white LED, blue LED (with ratio of 5 blue and 1 red LED) and red LED (with ratio of 5 red and 1 blue LED). Two set of LEDs were installed in each tier with the distance of $25 \mathrm{~cm}$ between LED and the top of hydroponic tray. The light intensity from each LED are similar with $100 \mu \mathrm{mol} / \mathrm{m}^{2} / \mathrm{s}$ from a $15 \mathrm{~W}$ power consumption. A timer was used to switch on the lighting system for 8 hours per day from 08:00 to 14:00.

\subsection{Data Collection and Analysis}

The data collection was taken on lettuce growth performance based on number and length of leaves, height and weight of plants and also amount of chlorophyll content. The 
number of leaves was counted manually once a week. The length of leaves was measured from apex to petiole and the height was measured from apex of leaves to top of peat disk using a ruler. Amount of chlorophyll content on the leaves was measured by using chlorophyll meter (Konica-Minolta SPAD 502 Plus) (Figure 2a). It was a non-invasive measurement; by clamped the meter over lettuce leaves and received an indexed chlorophyll content reading (-9.9 to 199.9) in less than 2 seconds. Average reading was taken from 3 different points. Weight of lettuce was measured using a digital weighing scale after harvest (Figure 2b). The significance different between means were analysed using one-way analysis of variance (ANOVA) as well as Tukey's multiple-comparison analysis. The significant level was set at $p \leq 0.05$.

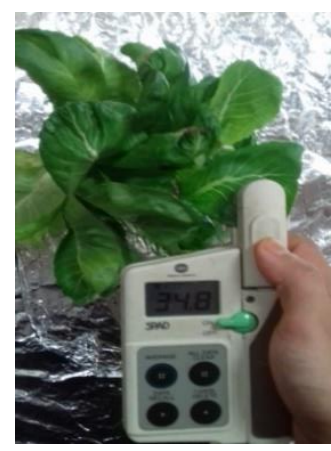

(a)

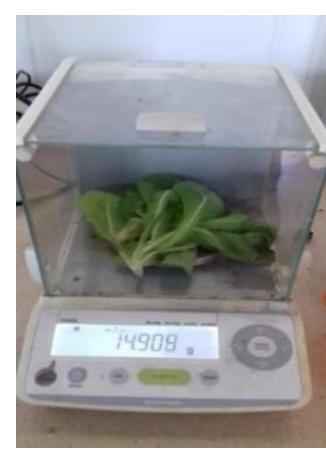

(b)

Figure 2. (a) Measuring the amount of chlorophyll content on the leaves by using SPAD 502 Plus Chlorophyll Meter, (b) Measuring lettuce weight after harvest on digital weighing scale.

\section{Results}

\subsection{Effect of different LEDs Treatment $n$ Lettuce Number of Leaves}

In the first initial week, the highest number of leaves is on red LED and the lowest is under control treatment. It shows that lettuce with supplemental lighting produce almost 5 times more leaves than lettuce without supplemental lighting. In week 2 dan 3 , lettuce under supplemental lighting continue to produce greater amount of leaves while lettuce without supplemental lighting started to shows senescence (Figure 3). Lettuce under red LED shows highest number in week 4 while lettuce under control treatment were completely died by week 4. One-way ANOVA shows that there are significant differences $(p \leq 0.001)$ between different colours of LED to number of lettuce leaves. Tukey HSD further analysis shows that the significance is between control treatment and lettuce under LED. There is no significant different between blue, red and white LED to number of lettuce leaves produced. 


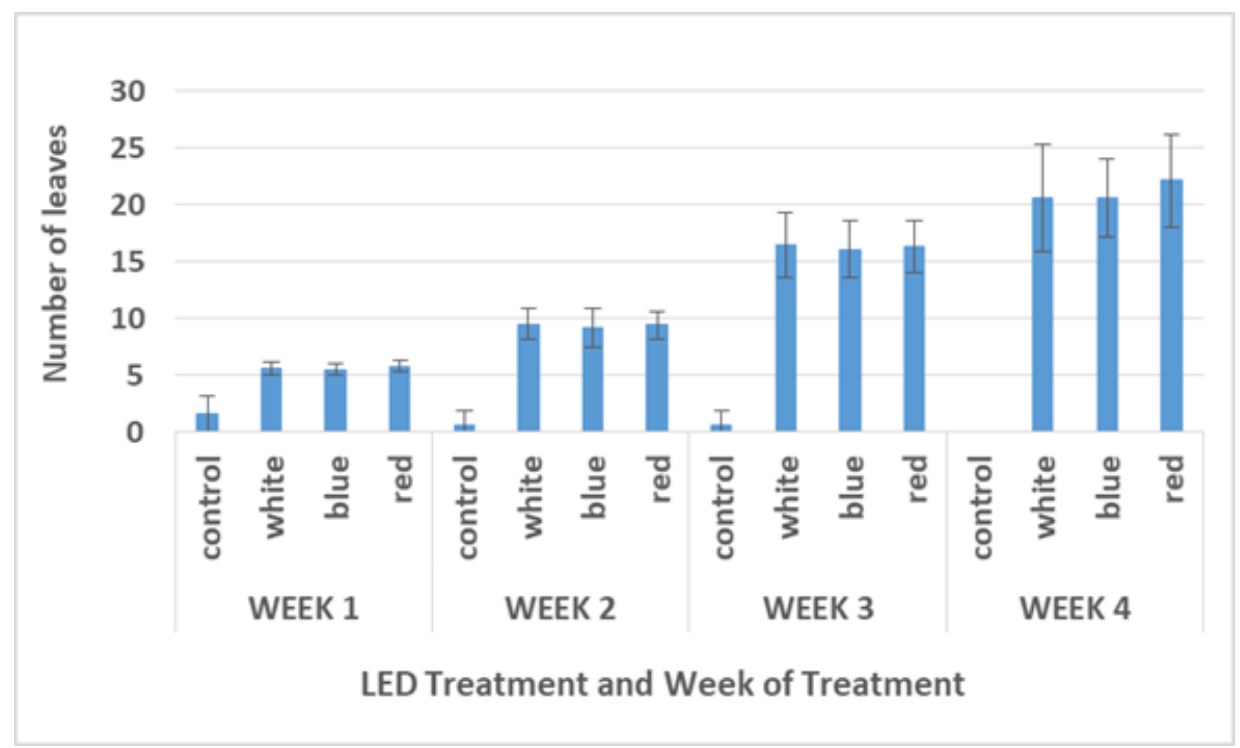

Figure 3. Number of leaves in each week under different LED treatments.

\subsection{Effect of Different LEDs Treatment on Lettuce Length of Leaves}

White LED shows highest leaves length for week 1 and week $2(4.12 \mathrm{~cm}$ and $8.15 \mathrm{~cm}$ respectively) with significant difference with blue LED $(2.17 \mathrm{~cm})$ and control treatment $(0.51$ $\mathrm{cm})$. However, during harvest at week 4, the highest leaves length was lettuce under red LED with average of $13.96 \mathrm{~cm}$ compared to blue LED $(11.03 \mathrm{~cm})$ and white LED $(12.51 \mathrm{~cm})$ (Figure 4). Based on Tukey HSD analysis, it shows that the length of leaves under red LED is significantly different with other treatment.

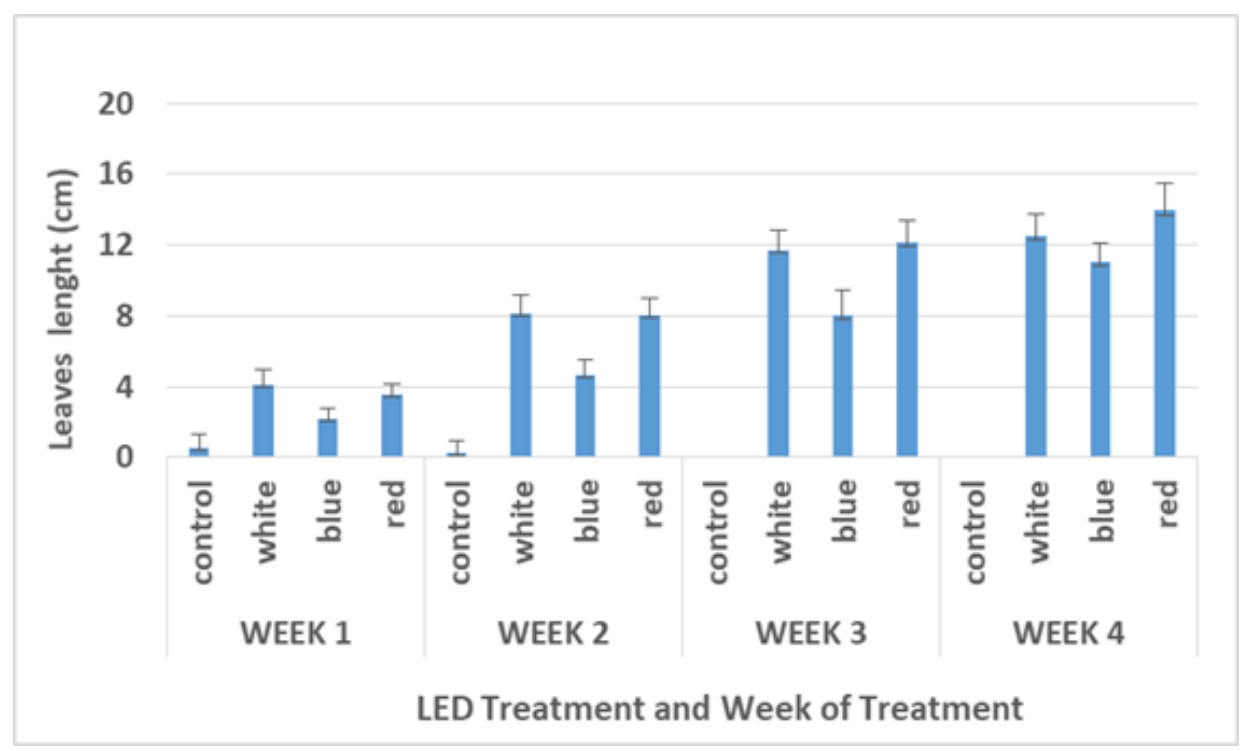

Figure 4. Length of leaves in each week under different LED treatments. 


\subsection{Effect of Different LEDs Treatment on Lettuce Height}

Figure 5 shows lettuce height in week 3 and 4 under different LED treatment. It shows that lettuce under white LED had highest plants in week $3(13.83 \mathrm{~cm})$ and week $4(17.06 \mathrm{~cm})$ compared to lettuce under red and blue. ANOVA and Tukey HSD analysis also shows that there is significant difference of lettuce height between white, blue and red LED. White LED improved lettuce height by $13 \%$ compared to red LED. Lettuce under blue LED had the lowest height while there is no data for lettuce under control treatment as lettuce were completely died by week 3 .

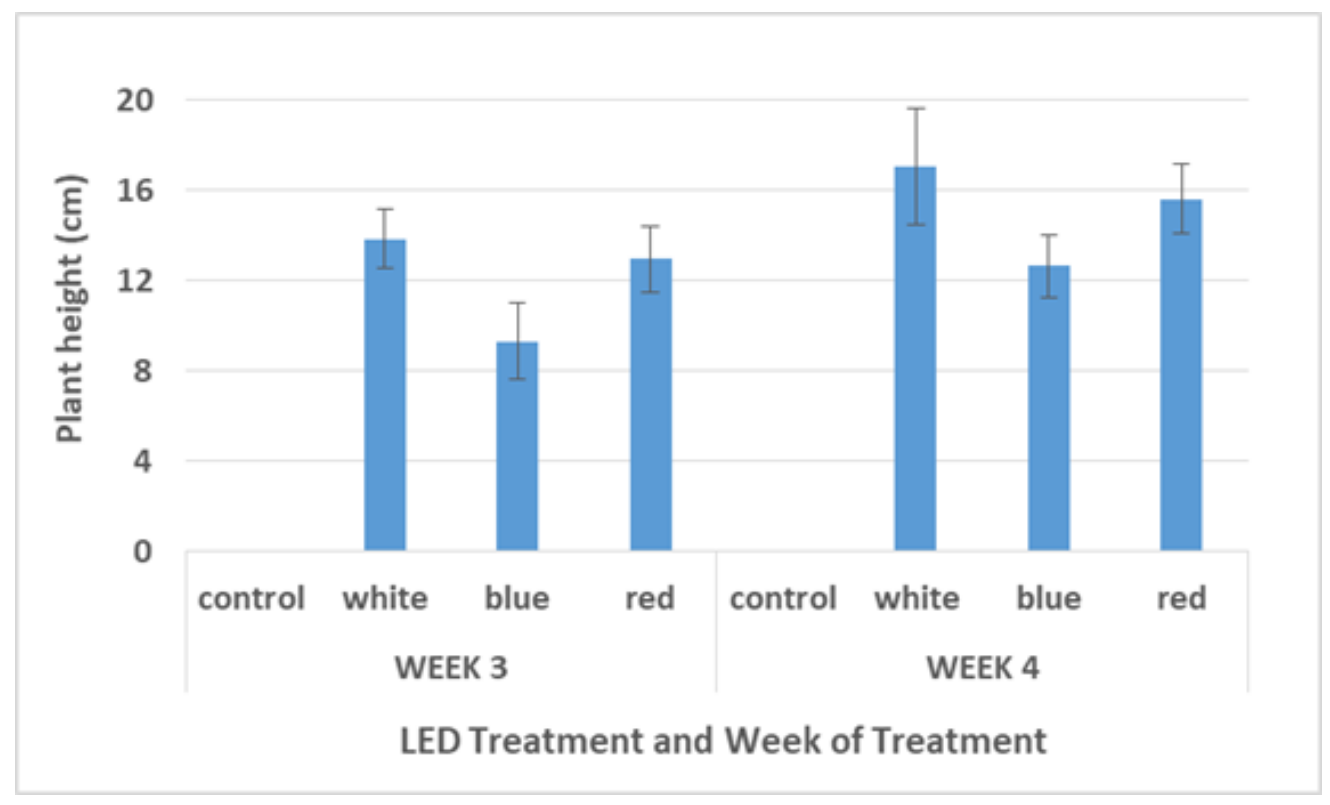

Figure 5. Height of lettuce plant in week 3 and 4 under different LED treatments.

\subsection{Effect of Different LEDs Treatment on Lettuce Chlorophyll Content}

Figure 6 shows the SPAD index of chlorophyll content from the SPAD Meter. Chlorophyll content in lettuce leaves during week 4 was found highest under white LED (173.57) followed by blue LED (43) and red LED (32.66). 


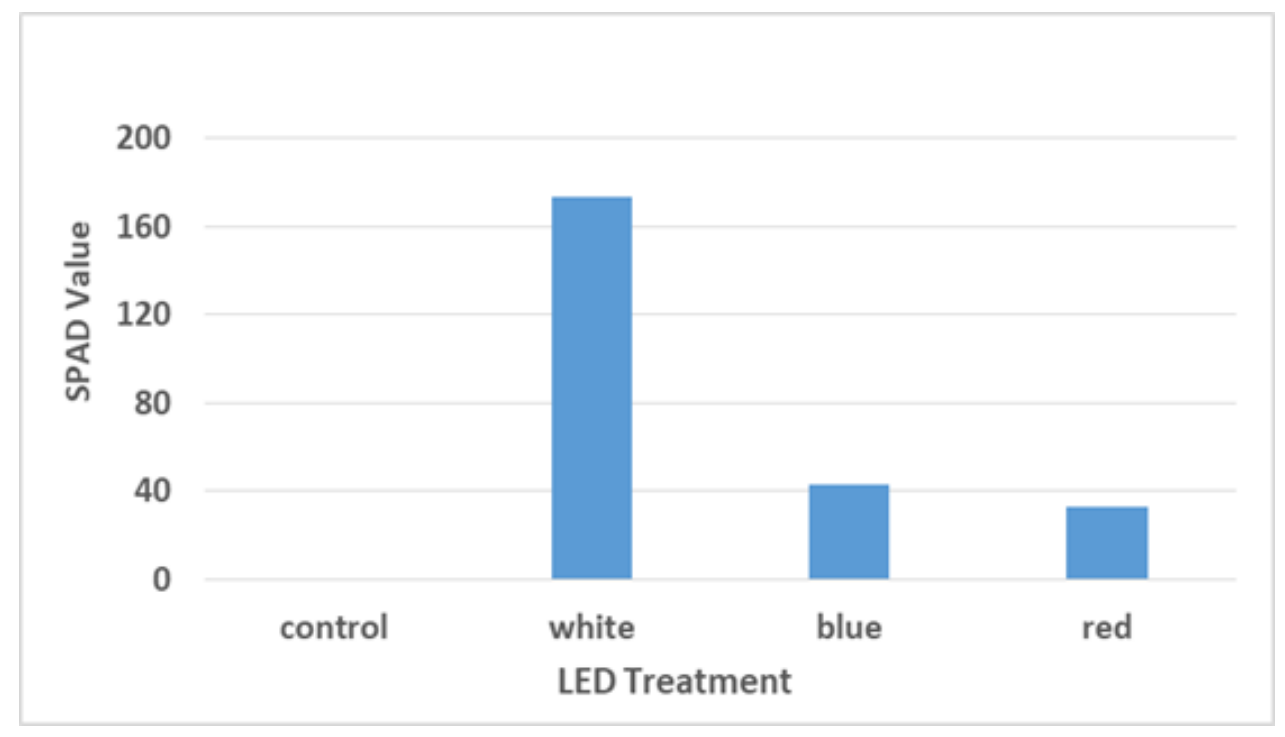

Figure 6. Amount of chlorophyll content in week 4 under different LED treatment.

\subsection{Effect of Different LEDs Treatment on Lettuce Weight}

Figure 7 shows that lettuce under red LED produce highest weight during harvest (22.63 g) followed by white LED (18.09 g) and blue LED (14.29 g). This conclude that red LED increased mass production of lettuce by $28 \%$ additional in weight compared to lettuce weight under white LED. There is significant difference in lettuce weight produced under red LED with white and blue LED.

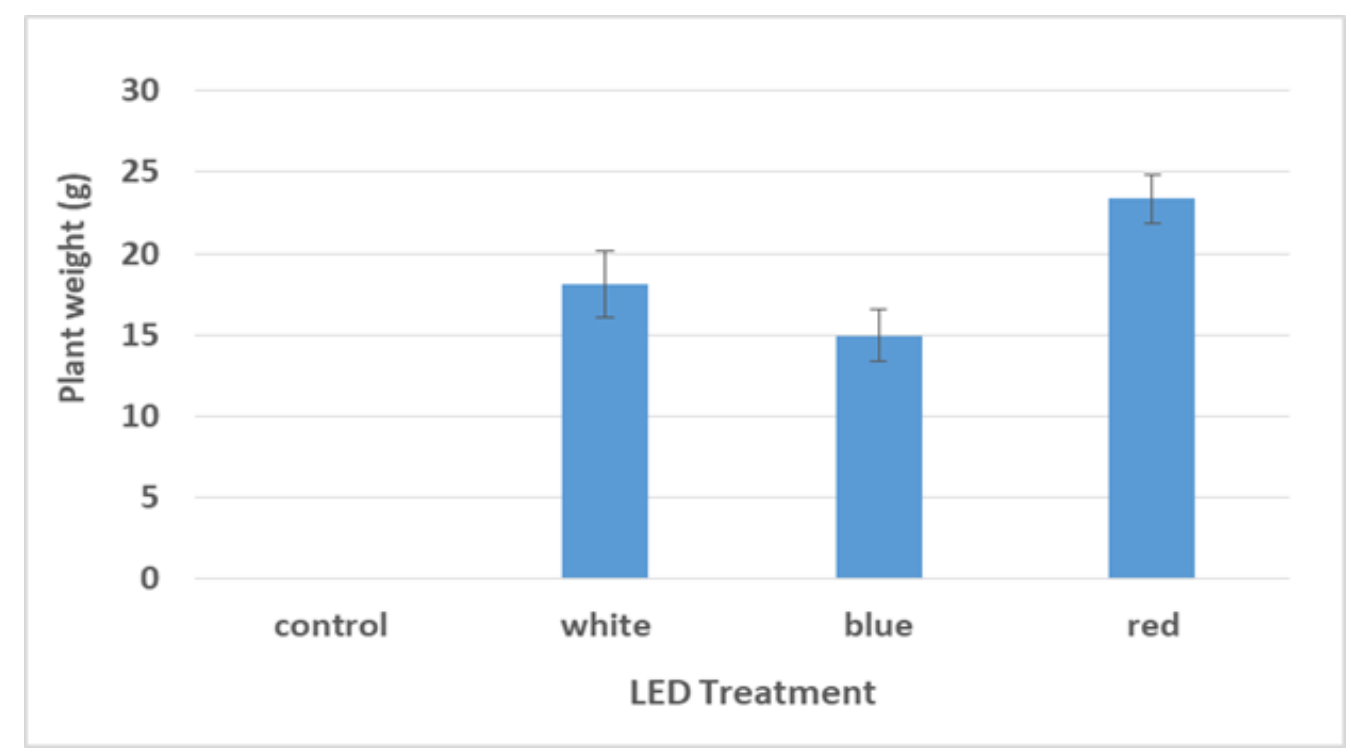

Figure 7. Lettuce weight during harvest under different LED treatment. 


\section{Discussions}

The research shows that LED supplemental lighting improved lettuce growth physiology for a vertical multi-tier hydroponic system. Red LED (ratio of 5 Red: 1 Blue) produced highest number of leaves and length. This results support by research finding of Miyashita et al. (1997) which shows that plants under red LEDs increased in shoot length compared to plants under white LED. Studies by Yanagi et al. (1996) also showed that lettuce plants grown under red LEDs alone had more leaves and longer stems compared to plants grown under blue LEDs only. Increased red light application resulted in higher leaf area and stem length, while increased in blue light application resulted in significant inhabitation of stem extension and thickening of leaf (Lu et al., 2012).

Lettuce height was found to be highest under white LED, while blue LED produced the lowest lettuce height. Nanya et al. (2012) also found that tomato plant under blue LED decreased in stem elongation growth but promote flowering. White LED also produce highest chlorophyll content in leaves compared to red and blue LED. Since white LED have the full spectrum of wavelength, this may contribute to the high chlorophyll content in the leaves. Research by Choi et al. (2015) showed that strawberries grown under white LED have higher level of chlorophyll and higher fruits production.

Since lettuce was sold based on its's weight, this parameter is important to figure out which LED give the highest production in weight basis. It shows that red LED has significantly increased the lettuce weight by $28 \%$ compared to blue LED. The highest value is also due to lettuce under red LED has highest number of leaves that contribute to the total weight produced.

It is interesting to understand the light intensity profile of these LED and find the best distance between the LED and crops to gain the optimum light intensity while avoiding heat stress from the light.

\section{Conclusions}

This result indicated that the red LED was the most effective in growth response of lettuce plants. This study also demonstrates the effectiveness of LED supplemental lighting in improving lettuce growth on vertical multi-tier hydroponic system. Although the mechanisms of changes in phytochemicals under different supplemental LED are not well known, the results demonstrated that supplemental LED could be strategically used to enhance growth of lettuce grown under red LED. 
Author Contributions: Nur Syahirah Talib: Methodology, Investigation, Data Curation, Formal analysis, Writing original draft. Diyana Jamaludin: Conceptualization, Resources, Review and Editing, Supervision. Nur Sakinah Abdul Malek: Formal analysis, Writing.

Funding: The authors gratefully acknowledge the financial support from Universiti Putra Malaysia with grant under UPM Grant Scheme (Project Code: GP-IPM/2018/9606700).

Acknowledgments: The authors would like to acknowledge Assistant Engineer Mr. Muhammad Azlan Othman and Mr. Tajul Urus Osman.

Conflicts of Interest: Declare conflicts of interest or state "The authors declare no conflict of interest."

\section{References}

Bourget, C.M. (2008). An introduction to light-emitting diodes. HortScience, 43, 1944-1946.

Choi, H. G., Moon, B. Y., \& Kang, N. J. (2015). Effects of LED light on the production of strawberry during cultivation in a plastic greenhouse and in a growth chamber. Scientia Horticulturae, 189, 22-31.

Goins, G.D., Yorio, N.C., Sanwo, M.M., et al. (1997). Photomorphogenesis, photosynthesis and seed yield of wheat plants grown under red light-emitting diodes (LEDs) with and without supplemental blue lighting. Journal of Experimental Botany, 48, 1407-1413.

Han, T., Vaganov, V. A., Cao, S., et al. (2017). Improving "color rendering" of LED lighting for the growth of lettuce. Scientific Reports, 7, 1-7.

Lefsrund, M. G., Kopsell, D.A., \& Sams, C.E. (2008). Irradiance from distinct wavelength light-emitting diodes affect secondary metabolites in kale. HortScience, 43, 2243-2244.

Lu, N., Maruo, T., Johkan, M., et al. (2012). Effects of supplemental lighting within the canopy at different developing stages on tomato yield and quality of single-truss tomato plants grown at high density. Environmental Control in Biology, 50(1), 1-11.

Mitchell, C.A. (2012). Plant lighting in controlled environments for space and earth applications. Acta Horticulturae, 956, 23-36.

Miyashita, Y., Kimura, T., Kitaya, Y., et al. (1997). Effects of red light on the growth and morphology of potato plantlets in vitro using light emitting diodes (LEDs) as a light source for micropropagation. Acta Horticulturae, 418, 169173.

Moreno-Monroy, A. I., Schiavina, M., \& Veneri, P. (2020). Metropolitan areas in the world. Delineation and population trends. Journal of Urban Economics, 103242.

Nanya, K., Ishigami, Y., Hikosaka, S., et al. (2012). Effects of blue and red light on stem elongation and flowering of tomato seedlings. Acta Horticuturae, 956, 261-266. https://doi.org/10.17660/ActaHortic.2012.956.29

Olle, M., \& Viršile, A. (2013). The effects of light-emitting diode lighting on greenhouse plant growth and quality. Agricultural and Food Science, 22(2), 223-234. https://doi.org/10.23986/afsci.7897

Stutte, G. W., Edney, S. \& Skerritt, T. (2009). Photoregulation of bioprotectant content of red leaf lettuce with light-emitting diodes. HortScience, 44, 79-82.

Yanagi, T., Okamoto, K. \& Takita, S. (1996). Effects of blue, red, and blue/red lights of two different PPF levels on growth and mor-phogenesis of lettuce plants. Acta Horticulturae, 440, 117-122. 
11 core guidelines to know before buying grow lights. (2020, September 2). Retrieved from https://www.urbanvine.co/blog/11-core-guidelines-urban-farmers-must-know-before-buying-grow-lights.

Copyright $\odot 2020$ by Talib, N. S. et al. and HH Publisher. This work is licensed under the Creative Commons 